\title{
Sustainable development methodology of fuel-energy complex of the republic of Uzbekistan
}

\author{
$G J$ Allaeva ${ }^{1}$ \\ ${ }^{1}$ Tashkent State Technical University named by Islam Karimov, Tashkent, Uzbekistan
}

\begin{abstract}
The article discusses the main elements sustainable development methodology of the fuel and energy complex of the Republic of Uzbekistan. Methods and ways of improving the organizational and economic mechanism of sustainable energy development are proposed.
\end{abstract}

Keywords. sustainable development, digital economy, nuclear energy, renewable energy sources, energy saving, energy efficiency, fuel and energy complex.

\section{Introduction}

Today, the sustainable development of enterprises of the fuel and energy complex is the core of development of modern society. Indicators of the energy sectors impacts the level of well-being of society, the activities of other sectors of the economy, and position in the world community. According to the IEA forecasts, in the next thirty years worldwide demand for all types of energy resources will increase significantly. Global gas production in 2019 increased by $3.8 \%$. Among the 15 leading gas producing countries, which account for more than $85 \%$ of world production, growth was noted in Russia, Norway, Saudi Arabia and Turkmenistan. At the same time, according to the conclusions of the International Energy Agency, gas consumption will more than double at the current level.

In recent years, our country has paid special attention to the sustainable development of the fuel and energy complex in the world market. Action strategies for five priority areas of the country's development in 2017-2021, priority tasks for "further modernization and diversification of the industry by transferring it to a new level, ... ... mastering the production of fundamentally new types of products and technologies, ... reducing the energy and resource intensity of the economy, widespread introduction in the production of energy-saving technologies, the use of renewable energy sources, increasing labor productivity in sectors of the economy;". Therefore, one of the main directions for improving enterprises of the fuel and energy complex in modern conditions is to improve the mechanisms for ensuring their sustainable development, contributing to the rational distribution of their resource potential, increasing the level of innovative activity and increasing the competitiveness of industry products.

Literature review. In the world scientific community in order to improve the methodology for assessing the organizational and economic mechanism of sustainable development of enterprises of the fuel and energy complex research is being carried out in the following priority areas: integration of the national fuel and energy system into the world market in the context of globalization; influence of effective integration of innovation processes and technologies on sustainable development of fuel and energy complex enterprises; the formation of tools for ensuring sustainable development of enterprises in the context of the development of the digital economy; attention is paid to ensuring the quality of the innovation environment and the efficiency of using the carriers of the innovative potential of enterprises in the fuel and energy complex, improving the organizational and economic mechanism for the sustainable development of enterprises in the fuel and energy complex.

The concept of sustainable development of enterprises adopted at the UN conference on environmental development in Rio de Janeiro (1992) has not lost its relevance to this day. This concept is a model for the development of civilization in which a balanced interaction of nature, society and economy is carried out. The main economic component of the concept of sustainable development is the optimal use of hydrocarbon energy resources and the use of nature-energy and materialsaving technologies.

The classic definition of "sustainable development" is proposed by the International Commission on Environment and Development. This interpretation reveals the essence of the analyzed definition: it takes into account resource constraints, the interaction of the biosphere and the noosphere.

However, ensuring sustainable functioning of the industry is difficult to predict due to the uncertainty of external and internal influences. The danger of instability is always present in an uncertain economic environment. Sustainable development has many definitions, concepts and interpretations. This is due to the fact that in relation to any 
economic system, you can choose the definition of sustainable development based on the goals, characteristics, properties and characteristics of the development of the system. Each author puts his own meaning into understanding, highlighting certain aspects.

Research methodology. The article used various types of analyzes: heuristic and expert assessment, statistical grouping, correlation, economic and statistical, graphical analysis and other methods.

Analysis and results. In our opinion, ensuring the sustainability of enterprises in the fuel and energy complex should be considered as one of the important areas of increasing the competitiveness of the national economy, and studied as a set of objective prerequisites for the effective development of the strategic sector of the national economy.

Based on the results of various studies in foreign and domestic scientific literature, the main approaches to the development and implementation of a strategy for the sustainable development of industrial enterprises, according to the author, are directed logical changes, the result of which is the effective sustainable development of the state's energy sector, which consists of the sustainable development of industries and enterprises. energy at the regional level, taking into account the backbone role of the fuel and energy complex of the republic. It has been determined that stability is retained by such systems that do not change their characteristics and properties under the action of external and internal disturbances. The process of sustainable development of the fuel and energy complex of the Republic of Uzbekistan should be associated with three "D": digitalization, decentralization, decarbonization which means the transition to digital energy, distributed energy and reduction of carbon dioxide emissions. The author proposes to supplement this list with one more term intellectualization, which would reflect the real state and development prospects of the energy systems of the future - a "smart", integrated energy system.

Energy Strategy of Uzbekistan until 2030 involves the creation of a sustainable system for ensuring national energy security. The process of implementing the Strategy for Fuel and Energy Supply of Uzbekistan for 2020-2030 and a comprehensive program for digitalization of the electric power industry for 2019-2021 is underway, which will be aimed at automating enterprise resource planning (ERP) and supervisory control and data acquisition (SCADA) processes.

One of the main priority issues in the development of the electric power industry in Uzbekistan is the development of generating capacities in such areas as thermal power stations (TPS), nuclear energy, renewable energy sources (RES) with the attraction of foreign direct investment.

The development of nuclear energy for our republic is a new innovative direction, where the priorities in this area are:

intellectualization of the development of nuclear energy, taking into account modern world trends;

the greening of nuclear energy, where careful handling and preservation of natural resources is considered a priority;

digitalization of nuclear energy is the most important component of the future energy sector and, accordingly, the state economy. Digital energetics is an energetics in which the relationship between producers and consumers of electricity has changed dramatically, as new, affordable technologies have appeared.

Studies have shown that in the digital economy, an important strategic direction for increasing the level of sustainability of enterprises is the automation and digitalization of production processes. The result of this is the national project "Implementation of an automated electricity metering and control system (AEMCS)", which has accelerated in recent years.

The author has improved a systematic approach to ensuring sustainable development, which involves considering the fuel and energy complex as an open system of an economic model (Figure 1).

We believe that the state of the fuel and energy complex depends on the stability of each element of the system. The essence of the functioning of the fuel and energy complex is reduced to the movement of information, energy, materials associated with the processing of input values (information, financial resources, material resources, ICT) and obtaining the desired results (energy resources, services, profit, information).

To analyze the functioning of the fuel and energy complex, the author singled out in its composition subsystems responsible for a certain type of activity (energy consumption, production of electricity and heat energy, energy supply). If the system is in a stable state, then its reaction to destabilizing influences can be as follows: adaptation; anticipation of possible changes; repayment of negative impacts. If the system is unstable, then the result of destabilizing influences can be stagnation, degradation, regression - downward development, the collapse of the system.

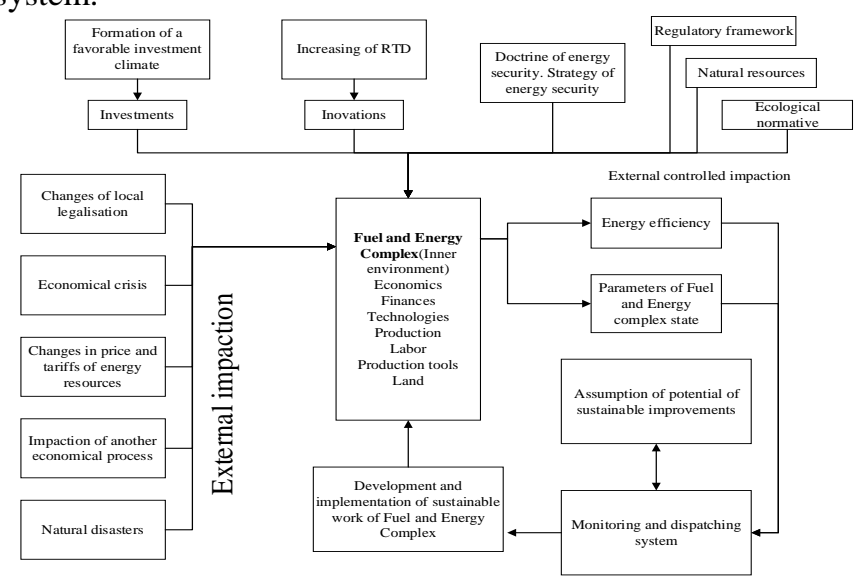

Fig. 1. The structure of the economic model of sustainable development of the fuel and energy complex.

Our studies have shown that the sustainable development of the fuel and energy complex is the transition of a system from one state to another, characterized by new properties and characteristics of the system, corresponding to the trends of the new time. Stability lies in the fact that after the transition from one state to another, the parameters of the state of the system, at the same time, do not deteriorate, in other words stay in the boundaries of stability. For an 
economic system, the main condition for sustainability is the provision of resources at the right time in the required amount and on acceptable terms. Resources can be exemplified as material flows, technologies, human resources, financial resources.

Discussion: It was revealed that the fuel and energy complex have orbital stability that is the ability of uninterrupted and reliable functioning with any changes in the internal and external environment, maintaining, and improving its characteristics during the transition to a new level of development, provided that the state parameters do not go beyond the permissible limits. Orbital stability is characterized by the fact that it is selected - a neighborhood beyond which the parameters of the system cannot go if for any undesirable deviation of the state parameters it is possible to return the process to the boundaries of stable operation with the help of a control action. If the values of the indicators characterizing the criteria go beyond the boundary of sustainability, then the economic system is threatened with destruction.

Orbital stability allows the fuel and energy complex to maintain a balance of state parameters when moving to a new level of development. The author defines the main conceptual elements of the orbital sustainable development of the fuel and energy complex (Figure 2). The institutional component, which is the technological basis for making managerial decisions in the framework of sustainable development of the fuel and energy complex creates economic, organizational, and legal conditions for development ensuring the formation of a favorable economic environment which in turn provides an inflow of investments necessary for modernization and transition to the path of innovative development.

Clarifying the trilemma of improving energy security based on sustainable development of the fuel and energy complex we believe that firstly the fuel and energy complex is characterized by orbital stability - the ability of the system to function ensuring uninterrupted and reliable production, and supply of fuel and energy resources to consumers, and development under changing internal and external conditions while maintaining and improving their characteristics during the transition to a new level of development, provided that the state parameters do not go beyond the permissible limits. Development is the process of improving technology, accounting, control, business processes, movement of material flows.

Secondly, energy security is the ability to provide uninterrupted and reliable supply of fuel and energy resources to consumers while leveling the emerging external and internal threats that destabilize the functioning of the fuel and energy complex.

Thirdly, the ecological component is the development of green energy based on rational use of natural resources, preserving the natural environment, and the production of energy from renewable sources.

Summarizing these three concepts, we can say that sustainable development is the process of ensuring energy, economic and environmental security, subject to effective environmental management. To overcome development imbalances and establish proportions, the structure of the system must be flexible and adaptable, and have the potential for improvement.

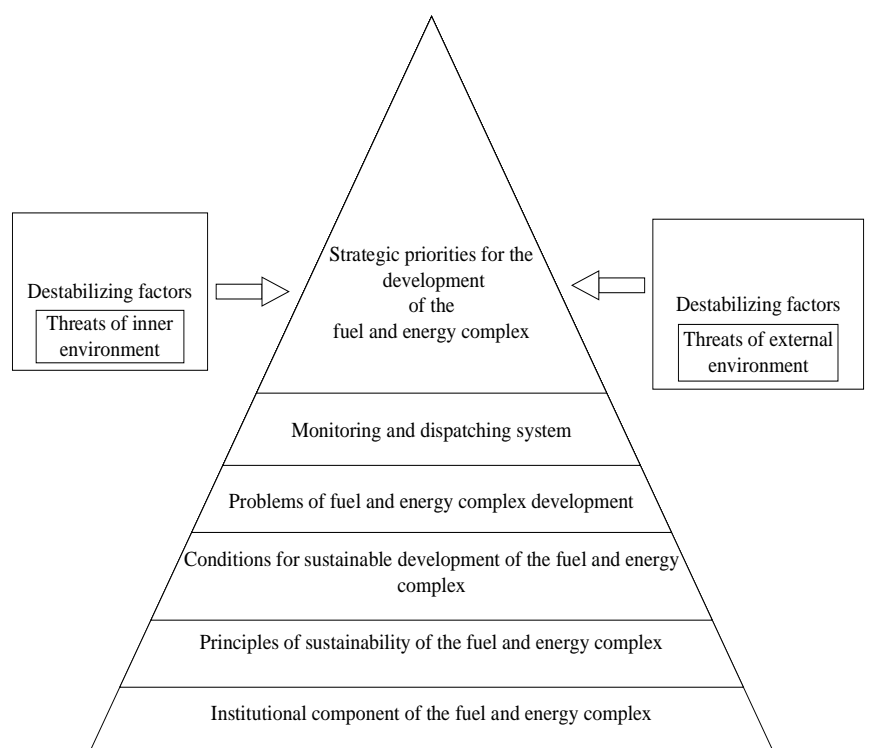

Fig.2. Elements of the concept of orbital sustainable development of the fuel and energy complex

Table 1

Main economic indicators of sustainable development of the enterprise and criteria for their assessment

\begin{tabular}{|c|c|c|}
\hline $\begin{array}{c}\text { Indicato } \\
\text { rs }\end{array}$ & Criteria & Unit \\
\hline \multirow[t]{3}{*}{ Market } & $\begin{array}{c}\text { Market share of product } \\
\text { sales }\end{array}$ & $\%$ \\
\hline & $\begin{array}{l}\text { Turnover in a specific } \\
\text { market }\end{array}$ & thousand sum /year \\
\hline & Share of cash in turnover & $\%$ \\
\hline \multirow{8}{*}{$\begin{array}{l}\text { Producti } \\
\text { on }\end{array}$} & $\begin{array}{l}\text { Commercial products in } \\
\text { actual and comparable prices }\end{array}$ & thousands sum \\
\hline & \begin{tabular}{|ll} 
Volume growth index \\
manufactured products
\end{tabular} & index \\
\hline & Products sold & thousands sum \\
\hline & Production costs & thousands sum \\
\hline & Cost growth index & index \\
\hline & $\begin{array}{l}\text { Share of variable costs in the } \\
\text { cost of production }\end{array}$ & specific gravity \\
\hline & Production per worker & $\begin{array}{c}\text { thousands sum./ } \\
\text { man/year }\end{array}$ \\
\hline & \begin{tabular}{|l}
$\begin{array}{l}\text { Percentage of orders } \\
\text { completed on time }\end{array}$ \\
\end{tabular} & $\%$ \\
\hline \multirow{3}{*}{ Social } & $\begin{array}{l}\text { Number of employees by } \\
\text { category }\end{array}$ & man \\
\hline & $\begin{array}{l}\text { The ratio of wages to } \\
\text { subsistence minimum }\end{array}$ & coefficient \\
\hline & $\begin{array}{l}\text { Average monthly wage ratio } \\
\text { employees to the average } \\
\text { monthly salary in the } \\
\text { country }\end{array}$ & coefficient \\
\hline \multirow{6}{*}{$\begin{array}{c}\text { Financial } \\
\text { and } \\
\text { economic }\end{array}$} & Working capital & thousands sum \\
\hline & Own working capital & thousands sum \\
\hline & Net profit & thousands sum/year \\
\hline & Net profitability & $\%$ \\
\hline & Current liquidity & coefficient \\
\hline & Fixed-asset turnover & c. $/ \mathrm{c}$. \\
\hline
\end{tabular}


Integration and interdependence of elements and the ability to regulate are important for the integrity of the system.

To assess the level of sustainable development of an enterprise, the following groups of indicators are taken in accordance with their role in the production process: market, production, social, financial and economic (Table 3). The information base is the financial statements of the organization, forms of state statistical reporting, data of enterprises that are not included in it.

The process of creating an information and analytical base for the analysis and construction of derived indicators for assessing the sustainable development of an enterprise is as follows: a) input of initial information on the enterprise; b) calculation of financial and economic indicators characterizing the position of the enterprise; c) analytical comparison of indicators; d) construction of a weighted index of the integral assessment of the sustainable development of the enterprise.

Ensuring sustainable economic development of the enterprise is one of the main tasks facing managers at all levels of management. The implementation of the principle of financial stabilization in the long term involves the development, selection and assessment of a financial strategy based on ensuring the financial stability and financial balance of the enterprise. In recent years a traditional method has been developed in assessing financial stability which is based on calculations of indicators calculated from the balance sheet data. However, the use of this technique which is quite simple to use is possible only for preliminary acquaintance with the financial condition of the enterprise.

Conclusions: The analysis made it possible to develop the following scientifically grounded proposals for a strategy for sustainable effective development and reform of the fuel and energy complex of the republic:

1. Intensification and intellectualization of energy efficiency and energy saving (reserve - 30-40\% of energy savings). This will require accelerated modernization of fixed assets, diversification of energy sources, pursuing a tough energy-saving policy, assessing the real costs of supplying the country, etc. It is necessary to introduce energy-efficient innovative technologies in the sector of residential, commercial and administrative buildings ("smart home", "smart city"), as well as network technologies (activeadaptive networks, energy Internet, information and analytical systems, etc.), that is.

2. Development of the national nuclear infrastructure, including the formation of a regulatory and legal framework, participation of the Republic of Uzbekistan in the global nuclear safety regime, ensuring the activities of the operating organization of a nuclear power plant, creating a regulatory framework for nuclear energy, ensuring transparency and openness to the public of the nuclear energy program, providing qualified personnel ...

3. Development of energy resources of wind and sun. In most countries of the world, extensive work is underway to diversify the energy mix, including by expanding the use of non-carbon renewable energy sources. According to the estimates of domestic and foreign experts, the real technical potential of solar and wind energy in Uzbekistan is at least 10 million $\mathrm{kW}$ of power in each direction.
4. Development of an innovative system of the fuel and energy complex based on stimulating demand for domestic technological developments, restructuring the costs of energy companies for research and development, development of network forms of organizing and promoting innovation and technology transfer, including expanded integration into international networks and others;

5. Development of interaction of energy companies with educational organizations and research centers; expansion of the practice of co-financing by the state and business entities of long-term applied and innovative research and scientific and technological development programs. These problems are of particular relevance as part of the implementation of the measures provided for in the Resolution of the President of the Republic of Uzbekistan Shavkat Miromonovich Mirziyoyev "On measures to further expand the participation of industries and sectors of the economy in improving the quality of training specialists with higher education" (July 27, 2017);

6. Creation and development of an information and analytical system for monitoring and forecasting the development of the fuel and energy complex of the Republic of Uzbekistan, which will facilitate the formation of highquality statistical and analytical reports, as well as fuel and energy balances for the future;

7. Improvement and development of the activities of the branch fund for innovative technologies in the fuel and energy complex with the participation of research institutes and educational institutions, private investors and others for the implementation of priority technologies in order to modernize the industry. In order to increase the efficiency of investment projects, active expansion of the scope of project management and the development of venture financing, which ensures continuous financing of promising technological solutions at all stages of the innovation cycle;

8. Implementation and improvement of modern organizational models of educational institutions, including a model of innovative scientific, educational and industrial clusters, a model of interaction between educational institutions within consortia (including with the participation of international universities). Implementation of initiatives for the formation of engineering education (with the updating of educational programs taking into account the needs of production), aimed at deepening students' practical knowledge and technical foundations of the profession, as well as at developing skills in the creation and operation of innovative technologies.

\section{References}

1. Decree of the President of the Republic of Uzbekistan No. PD-5598 dated December 13, 2018 "On additional measures to introduce the digital economy, electronic government and information systems in the state administration of the Republic of Uzbekistan."

2. Strategy of actions in five priority directions of development of the Republic of Uzbekistan for 2017-2021.

3. Resolution of the President of the Republic of Uzbekistan on the Concept of the development of nuclear energy in the Republic of Uzbekistan for the period 20192029. No. PD-4165 dated 07.02.2019 
4. No. PD-5544 dated September 21, 2018 "On the strategy of innovative development of the Republic of Uzbekistan for 2019-2021"

5. Gurieva L. Strategy of sustainable development of the region / L. Gurieva // Problems of theory and practice of management. - 2012. - No. 2.

6. Dudarev A.S. Factors of sustainable economic development / A.S. Dudarev // Entrepreneur. - 2013. - No. 8. - S. 56-59.

7. Tatiana Stanislavovna Rotar. Sustainable development of the enterprise: the essence and methodology for calculating the integral index of sustainable development of airlines. Economics, Statistics and Informatics. No. 4, 2015. Pp. 149 153.

8. Kucherova E.N. A modern approach to sustainable development of an enterprise / Bulletin of the Orenburg State University. 2007. - No. 9 (73). - P. 76-81. 